\title{
Implementing Mobile Health-Enabled Integrated Care for Complex Chronic Patients: Intervention Effectiveness and Cost-Effectiveness Study
}

Jordi de Batlle ${ }^{1,2}, \mathrm{PhD}$; Mireia Massip ${ }^{1}$, BSc; Eloisa Vargiu ${ }^{3}, \mathrm{PhD}$; Nuria Nadal ${ }^{4}$, MD; Araceli Fuentes ${ }^{5}$, MD; Marta Ortega Bravo ${ }^{6,7,8}$, MD; Felip Miralles ${ }^{3}$, PhD; Ferran Barbé ${ }^{1,2}$, MD; Gerard Torres ${ }^{1,2}$, MD; CONNECARE-Lleida Group 9

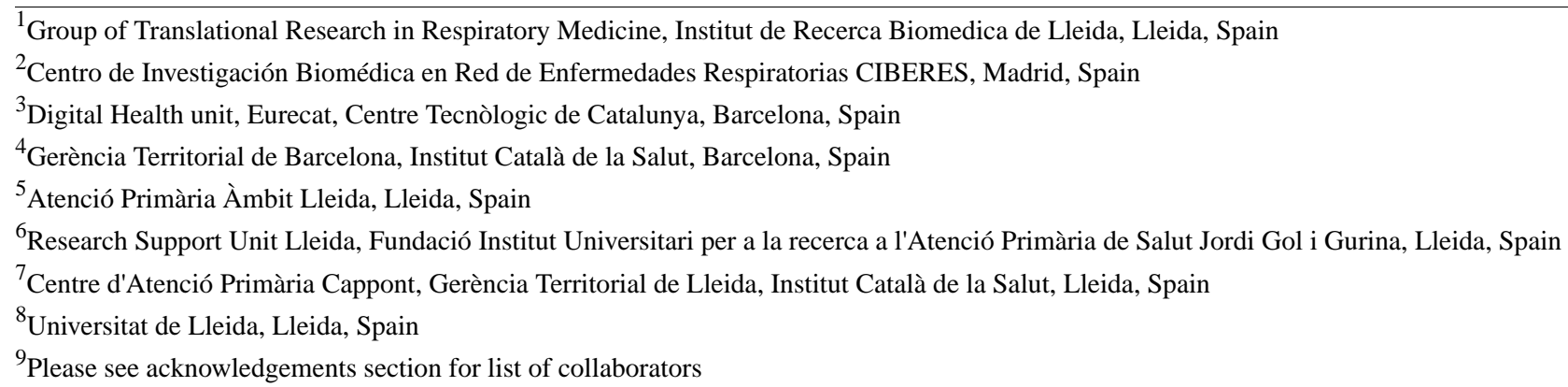

Corresponding Author:

Gerard Torres, MD

Group of Translational Research in Respiratory Medicine

Institut de Recerca Biomedica de Lleida

80 Rovira Roure

Lleida, 25198

Spain

Phone: 34973705372

Email: gtorres@gss.cat

\section{Abstract}

Background: Integrated care can generate health and social care efficiencies through the defragmentation of care and adoption of patient-centered preventive models. eHealth can be a key enabling technology for integrated care.

Objective: The aim of this study was to assess the effectiveness and cost-effectiveness of the implementation of a mobile health (mHealth)-enabled integrated care model for complex chronic patients.

Methods: As part of the CONNECARE Horizon 2020 project, a prospective, pragmatic, two-arm, parallel implementation trial was held in a rural region of Catalonia, Spain. During 3 months, elderly patients with chronic obstructive pulmonary disease or heart failure and their carers experienced the combined benefits of the CONNECARE organizational integrated care model and the eHealth platform supporting it, consisting of a patient self-management app, a set of integrated sensors, and a web-based platform connecting professionals from different settings, or usual care. We assessed changes in health status with the 12-Item Short-Form Survey (SF-12), unplanned visits and admissions during a 6-month follow up, and the incremental cost-effectiveness ratio (ICER).

Results: A total of 48 patients were included in the integrated care arm and 28 patients receiving usual care were included in the control arm (mean age 82 years, SD 7 years; mean Charlson index 7, SD 2). Integrated care patients showed a significant increase in the SF-12 physical domain with a mean change of +3.7 (SD 8.4) $(P=.004)$ and total SF-12 score with a mean change of +5.8 (SD 12.8) $(P=.003)$; however, the differences in differences between groups were not statistically significant. Integrated care patients had 57\% less unplanned visits $(P=.004)$ and 50\% less hospital admissions related to their main chronic diseases $(P=.32)$. The integrated care program generated savings in different cost scenarios and the ICER demonstrated the cost-effectiveness of the program.

Conclusions: The implementation of a patient-centered mHealth-enabled integrated care model empowering the patient, and connecting primary, hospital, and social care professionals reduced unplanned contacts with the health system and health costs, 
and was cost-effective. These findings support the notion of system-wide cross-organizational care pathways supported by mHealth as a successful way to implement integrated care.

(JMIR Mhealth Uhealth 2021;9(1):e22135) doi: 10.2196/22135

\section{KEYWORDS}

chronic disease; cost-benefit analysis; delivery of health care, integrated; mHealth; eHealth; quality of life

\section{Introduction}

The last decades have led to rapidly aging populations and an increased burden of chronic diseases [1]. In this scenario, health and social care providers struggle to contain costs while providing an adequate response to the population's care needs. Traditional care models suffer from care fragmentation. That is, the different care settings fail to communicate with each other effectively, and patients have to undergo repeated tests and changes in prescribed drugs, ultimately prompting feelings of starting anew after every transition [2]. Additionally, the focus is still on the diseases rather than on the patients, which leaves patients and their carers as passive actors [2]. Therefore, there is a need for a profound redesign of how care is provided to elderly patients with chronic conditions to ensure quality and sustainability [3]. Integrated care models aim to generate health and social care efficiencies through the defragmentation of care, promotion of collaboration and continuity of care across settings, adoption of patient-centered models, and prioritization of preventive models [4]. However, few of these models have attempted to and succeeded in simultaneously tackling all of the above-mentioned measures [4]. eHealth and mobile health (mHealth) can be the key enabling technologies allowing for such a paradigm shift [5].

The Personalised Connected Care for Complex Chronic Patients (CONNECARE) project is a Horizon 2020 European Union Research and Innovation project aiming to co-design, develop, deploy, and evaluate a novel smart and adaptive organizational integrated care model for complex chronic patients (CCP) [6]. From April 2016 to December 2019, the project successfully co-designed, by means of an iterative patient-centered process involving patients and stakeholders across different health settings, an organizational model for integrated care and an eHealth platform to support the model. The integrated care model promotes collaboration among professionals of different care settings (family physicians, hospital specialists, and social workers), prioritizes home-based prevention over institutional reactive care, and fosters patient empowerment. The use of a web-based platform offers a cross-setting web-based Smart Adaptive Case Management (SACM) system for professionals, and an mHealth self-management system with three-level monitoring features allowing for patient empowerment.

As part of the CONNECARE project, a novel mHealth-enabled integrated care model was implemented in Lleida, Spain. The existing care model in Lleida is limited by the scarce communication between professionals of different care settings, with different electronic medical record (EMR) systems in hospitals and primary care centers (Argos SAP and ECAP [7], respectively), and patients playing a passive role throughout the care path. We here describe the results of the implementation of an mHealth-enabled integrated care model for the community-based prevention of unplanned hospital-related events in CCP with a high risk for hospitalization.

\section{Methods}

\section{Study Design}

This was a prospective, pragmatic, two-arm, parallel implementation trial comparing care as usual to a 3-month mHealth-enabled integrated care intervention. The study was conducted from July 2018 to August 2019 in Lleida, which is a large rural area of over $4300 \mathrm{~km}^{2}$, including two tertiary hospitals (University Hospital Arnau de Vilanova and University Hospital Santa Maria) and a network of 23 primary care centers spread across the whole territory, providing service to 400,000 citizens.

\section{Target Population}

Home-dwelling patients with chronic conditions and a history of hospitalizations were recruited for this study. The eligibility criteria were aged $\geq 55$ years; admitted to hospital for a respiratory or cardiovascular event (ie, chronic obstructive pulmonary disease exacerbation or heart failure decompensation); living at home and discharged back to the community; no dementia or cognitive impairment (Global Deterioration Scale score < 5 [8]); Length, Acuity, Comorbidities and Emergency score > 7 [9]; and passing a basic technological test assessing home connectivity and patients' or carers' competences with the use of technology. The basic technological test is shown in Multimedia Appendix 1.

\section{Recruitment}

Patients were recruited during an unanticipated admission to the hospital through the emergency room (ER). They were identified based on EMR data and were contacted by a case manager before discharge. After the recruitment of patients to the intervention arm, an active search for a matched control with similar characteristics began. All patients and their carers, regardless of study arm, received a face-to-face explanation about the study.

\section{Intervention}

Patients in the intervention arm experienced an integrated care model, including (i) preliminary assessment of the patient's health status using several questionnaires, tests, and indices specific to their main chronic diseases and social needs; (ii) a self-management app, with status and performance reports, a virtual coach with customizable automated feedback, and full communication with the care team; (iii) a Fitbit Flex 2 digital activity tracker [10] and any additional sensor deemed necessary by the care team [11], including a digital pulse-oximeter, digital 
scale, and digital blood pressure monitor, that were fully integrated into the self-management app; (iv) a patient profile in the SACM web-based platform, accessible to all members of the care team (family physicians, hospital specialists, and social workers), that was used for coordination and communication among professionals in the different settings, and to contact the patient when needed; and (v) assignment of a case manager in charge of supervising the whole process and serving as the main patient contact point. Additional details on the CONNECARE integrated care model and the supporting eHealth platform can be found in Multimedia Appendix 1. Patients in the control arm experienced care as usual, managed from primary care. After discharge from the initial 90 days of usual care for integrated care management, all patients were passively followed up for an additional 3 months.

\section{Data Collection}

Variables characterizing the patients were collected at recruitment using the SACM in tablet or desktop computers, including age, sex, main chronic disease(s), Charlson index of comorbidities [12], quality of life (QoL) as measured by the 12-Item Short-Form Survey (SF-12) [13], Barthel index for Activities of Daily Living [14], Hospital Anxiety and Depression scale [15], assessment of dwelling characteristics, main medications, Pfeiffer mental status questionnaire [16], and tobacco and alcohol consumption. The main outcomes were: (i) intervention effectiveness, as measured by the changes in the SF-12 health questionnaire's physical and mental domains (baseline vs discharge); (ii) use of health care resources after 6 months, and estimated associated costs based on Catalan Health Department official data [17]; and (iii) cost-effectiveness, based on the improvement in QoL relative to costs, assessed by means of the incremental cost-effectiveness ratio (ICER); all costs are described in US \$ (conversion factor: $1 €=1.21$ US \$). Additional details on cost estimations are described in Multimedia Appendix 1. The use of health care resources was collected from EMRs, which included hospital admissions, ER visits, visits to primary care, and visits to hospital specialists. Additionally, each admission or visit was assessed regarding its relation to the patient's chronic diseases as a binary variable (related or unrelated).

\section{Statistical Analyses}

Participants' baseline characteristics are summarized as n (\%), mean (SD), or median (IQR) as appropriate. Comparisons between baseline characteristics of patients in the integrated care and control groups were performed using the $\chi^{2}$ test, $t$ test, or Kruskal-Wallis test, as appropriate. A paired $t$ test was used to compare baseline to discharge values with respect to the SF-12 domains. Linear regression models were used to assess differences in the changes experienced by patients in the two groups. Negative binomial regression models were used to assess differences in the number of visits and admissions. Models were adjusted by age, sex, and Charlson comorbidity index. The ICER was calculated in relation to the SF-12 total score in three different scenarios: $100 \%, 150 \%$, and $200 \%$ estimated cost of the integrated care program. Data analyses were conducted using Stata version 12.1 (StataCorp, College Station, TX, USA). The threshold for significance was $\mathrm{P}<.05$.

\section{Ethical Considerations}

This study was approved by Ethics Committee of Hospital Arnau de Vilanova (CEIC-1685) and all patients provided written informed consent. All collected data were handled and stored in accordance with current national and international legislation.

\section{Results}

Up to 112 patients were screened for eligibility. After excluding patients not meeting the inclusion criteria, 52 patients were recruited for the mHealth-enabled integrated care arm and 35 patients were recruited for the usual care arm. Final analyses were based on 48 integrated care and 28 control patients completing the follow up (Figure 1).

Figure 1. Study flowchart. EMR: electronic medical record.

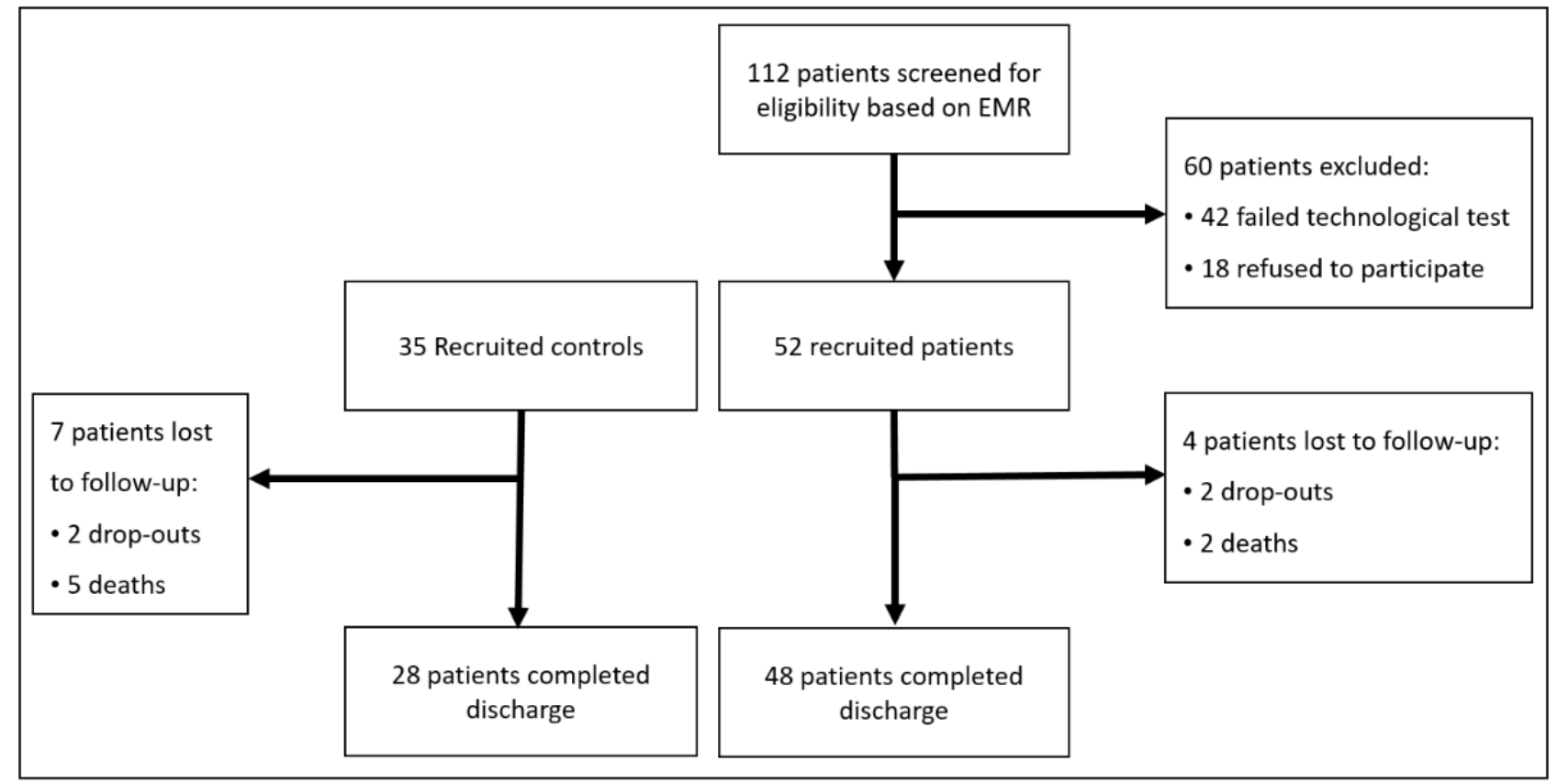


The patients' baseline characteristics are shown in Table 1. index between the patients in the two arms.

There were no significant differences in mean age or Charlson

Table 1. Baseline characteristics of patients in the usual care and integrated care (IC) arms.

\begin{tabular}{|c|c|c|c|}
\hline Characteristic & Usual care $(\mathrm{n}=28)$ & $\mathrm{IC}(\mathrm{n}=48)$ & $P$ value $^{\mathrm{a}}$ \\
\hline Sex (male), n (\%) & $17(61)$ & $24(50)$ & .37 \\
\hline Age (years), mean (SD) & $82(8)$ & $82(7)$ & .88 \\
\hline Charlson score, mean (SD) & $7.4(2.1)$ & $6.7(2.0)$ & .15 \\
\hline $\mathrm{LACE}^{\mathrm{b}}$ score, median (IQR) & $15(13-17)$ & $14(12-17)$ & .38 \\
\hline Barthel score, median (IQR) & $90(72.5-95)$ & $90(67.5-100)$ & .40 \\
\hline $\mathrm{HAD}^{\mathrm{c}}$ anxiety score, mean (SD) & $4.9(3.5)$ & $4.3(2.7)$ & .44 \\
\hline HAD depression score, mean (SD) & $5.6(2.9)$ & $5.7(2.3)$ & .95 \\
\hline Pfeiffer intact intellectual functioning, $\mathrm{n}(\%)$ & $21(75)$ & $37(77)$ & 67 \\
\hline GDS $^{\mathrm{d}}$, no cognitive decline, n (\%) & $27(96)$ & $44(92)$ & .25 \\
\hline
\end{tabular}

${ }^{\mathrm{a}} \chi^{2}$ test, $t$ test, or Kruskal-Wallis equality-of-populations rank test, as appropriate.

bACE: Length, Acuity, Comorbidities, and Emergency score.

${ }^{\mathrm{c}} \mathrm{HAD}$ : Hospital Anxiety and Depression scale.

${ }^{\mathrm{d}}$ GDS: Global Deterioration Scale.

Table 2 shows the changes in QoL (SF-12 domains) from baseline to discharge. Patients in the integrated care arm showed a significant increase in the SF-12 physical domain and total

SF-12 scores. The differences in QoL between integrated care and control patients favored the integrated care patients but did not achieve statistical significance.

Table 2. Changes in health status in the usual care and integrated care arms.

\begin{tabular}{|c|c|c|c|c|}
\hline $\mathrm{SF}-12^{\mathrm{a}}$ score & Baseline, mean (SD) & Discharge, mean (SD) & Change, mean (SD) & $P$ value ${ }^{\mathrm{b}}$ \\
\hline \multicolumn{5}{|l|}{ Physical } \\
\hline Usual care & $29.6(8.3)$ & $31.6(9.0)$ & $+2.0(7.5)$ & .16 \\
\hline Integrated care & $29.0(7.3)$ & $32.7(9.4)$ & $+3.7(8.4)$ & .004 \\
\hline Difference & $-0.6(2.0)$ & $+1.1(2.0)$ & $+1.7(2.9)$ & .21 \\
\hline \multicolumn{5}{|l|}{ Mental } \\
\hline Usual care & $47.0(13.5)$ & $45.8(15.5)$ & $-1.2(11.9)$ & .59 \\
\hline Integrated care & $51.8(9.9)$ & $53.9(11.5)$ & $+2.0(11.2)$ & .21 \\
\hline Difference & $+4.2(3.7)$ & $+9.2(3.7)$ & $+5.0(5.2)$ & .10 \\
\hline \multicolumn{5}{|l|}{ Total } \\
\hline Usual care & $76.6(13.9)$ & $77.4(20.5)$ & $+0.8(14.7)$ & .77 \\
\hline Integrated care & 80.8 (11.9) & $86.6(16.3)$ & $+5.8(12.8)$ & .003 \\
\hline Difference & $+4.2(3.7)$ & $+9.2(3.7)$ & $+5.0(5.2)$ & .10 \\
\hline
\end{tabular}

${ }^{\mathrm{a}} \mathrm{SF}-12$ : 12-Item Short-Form Survey.

${ }^{\mathrm{b}}$ Paired $t$ test comparing baseline and discharge measures; linear regression predicting the difference on baseline and discharge measures according to intervention arm, adjusted by age, sex, and Charlson index.

Table 3 shows that integrated care patients had 57\% less admissions related to their main chronic diseases, although this unplanned visits, representing a significant difference. Integrated care patients also experienced a $50 \%$ reduction in hospital 
Table 3. Total use of health services during the follow-up period.

\begin{tabular}{lllll}
\hline Health service & $\begin{array}{l}\text { Usual care }(\mathrm{n}=28), \text { mean } \\
(\mathrm{SD})\end{array}$ & $\begin{array}{l}\text { Integrated care }(\mathrm{n}=48), \\
\text { mean (SD) }\end{array}$ & $P$ value $^{\mathrm{a}}$ & Adjusted $P$ value $^{\mathrm{b}}$ \\
\hline All unplanned visits & $2.3(3.1)$ & $1.0(1.1)$ & .001 & .004 \\
Unplanned visits related to chronic disease & $0.9(1.2)$ & $0.4(0.6)$ & .01 & .04 \\
All hospital admissions & $0.5(0.8)$ & $0.4(0.6)$ & .18 & .50 \\
$\begin{array}{l}\text { Hospital admissions related to chronic } \\
\text { disease }\end{array}$ & $0.4(0.7)$ & $0.2(0.5)$ & & .32 \\
\hline
\end{tabular}

${ }^{\mathrm{a}}$ Negative binomial regression model.

${ }^{\mathrm{b}}$ Negative binomial regression model adjusted by age, sex, and Charlson comorbidity index.

The results for the within trial costs and cost-effectiveness analyses for all unplanned visits and hospital admissions are shown in Table 4, and those for unplanned visits and hospital admissions related to the patient's main chronic diseases are shown in Table S1 of Multimedia Appendix 1. The integrated care program generated savings from US $\$ 584$ to $\$ 1434$ per patient, depending on the scenarios. The integrated care program was cost-effective according to the ICER, performing better in terms of QoL while reducing overall expenses.

Table 4. Within trial costs (average cost per patient) and cost-effectiveness considering all unplanned visits and hospital admissions in three integrated care (IC) program cost scenarios.

\begin{tabular}{|c|c|c|c|c|}
\hline Related cost & Usual care $(\mathrm{n}=28)$, US $\$$ & IC $(n=48)$, US \$ & Difference & $\mathrm{ICER}^{\mathrm{a}}$ \\
\hline Unplanned visits $^{\mathrm{b}}$ & 173.62 & 78.02 & -95.60 & $\mathrm{~N} / \mathrm{A}^{\mathrm{c}}$ \\
\hline Hospital admissions ${ }^{b}$ & 3069.94 & 2404.15 & -665.79 & N/A \\
\hline Total medical costs per patient & 3243.56 & 2482.17 & -761.39 & N/A \\
\hline \multicolumn{5}{|c|}{ Scenario 1: $100 \%$ IC program costs } \\
\hline CONNECARE program & 0 & 85.92 & 85.92 & N/A \\
\hline Total costs per patient & 3243.56 & 2568.09 & -675.47 & -135.64 \\
\hline \multicolumn{5}{|c|}{ Scenario 2: $150 \%$ IC program costs } \\
\hline CONNECARE program & 0 & 128.89 & 128.89 & N/A \\
\hline Total costs per patient & 3243.56 & 2611.06 & -632.50 & -127.01 \\
\hline \multicolumn{5}{|c|}{ Scenario 3: $200 \%$ IC program costs } \\
\hline CONNECARE program & 0 & 171.84 & 171.84 & \\
\hline Total costs per patient & 3243.56 & 2654.01 & -589.55 & -118.39 \\
\hline
\end{tabular}

aCER: incremental cost-effectiveness ratio; incremental cost associated with 1 additional point gain in 12-Item Short-Form Survey (SF-12).

${ }^{\mathrm{b}}$ Costs based on the Catalan Institute of Health official pricing (CVE-DOGC-A-13051031-2013).

${ }^{\mathrm{c}}$ N/A: not applicable.

\section{Discussion}

\section{Principal Results}

The prospective assessment of the implementation of an mHealth-enabled integrated care program for CCP management showed a reduction in the number of unplanned contacts with the health system, generated substantial savings for the health system without having any negative impact on QoL or clinical outcomes, and demonstrated cost-effectiveness.

\section{Strengths and Limitations}

A key strength of this study was the effort to involve, from the very beginning, all of the stakeholders from different organizations that would be actors in a large-scale deployment of the mHealth-enabled integrated care program. This is especially relevant as the lack of cooperation between organizations, teams, or professions is a recurrent barrier toward the implementation of integrated care [4]. Other relevant strengths included: (i) the involvement of informal carers in the integrated care process, as close relatives of patients are usually the link between the patients and the health system, and such informal carers were key for facilitating the use of the self-management app in patients with a mean age over 80 years; (ii) the use of a self-management app (including a virtual coach with customizable automated feedback, full communication with the care team, and active monitoring), as such apps can significantly enhance doctor-patient relationships [18] and detect worsening in patient conditions or frailty [19]; (iii) the promotion and assessment of patients' physical activity, as mobility impairment is found in one third of people over 65 years [20]; (iii) the implementation region, a large rural area of 
over $4300 \mathrm{~km}^{2}$, which can benefit the most from community-based integrated care initiatives that preclude unnecessary travels to the hospital; and (iv) the prospective study design.

In terms of limitations, although the organizational model did not experience substantial changes throughout the implementation period, the supporting technological platform was in a permanent process of refinement and addition of new functionalities. This implied that the integrated care experience was richer in patients who were recruited near the end of the implementation study compared with that of patients recruited at the very beginning. Similarly, this had a considerable impact on the health care professionals, who had to cope with a platform in constant development and that was not fully integrated with the existing EMR. However, directly participating in a dynamic development and implementation process allowed the professionals to feel engaged and propose changes, and for new features to be developed, which ultimately resulted in not a single professional dropping out of the implementation study. Other limitations were: (i) the relatively small number of patients involved in this first phase of the deployment, which ultimately affected statistical power; (ii) the assumptions held while determining the costs of the mHealth-enabled integrated care program intervention, as well as the lack of assessment of indirect (societal) savings; and (iii) the strategy of centralizing the entry points to the integrated care program in the hospital (after ER admission), as it is important that system-wide cross-organizational care pathways consider multiple entry points [21]. In this regard, upcoming phases of the implementation will consider additional entry points such as the primary care centers.

\section{Comparison With Existing Literature}

The impact of the implementation of the integrated care model was assessed in three domains: (i) patients' QoL, (ii) use of health services, and (iii) economics. In the first domain, QoL, the integrated care model performed slightly better than usual care, with positive differences-in-differences values but not reaching statistical significance. This result is in line with a 2017 umbrella review concluding that integrated care interventions showed mixed results in terms of improving patients' QoL [22]. In this sense, it must be noted that the short duration of the implemented intervention (3 months) could have limited its capacity to affect the overall QoL. Nevertheless, the short duration did not preclude obtaining excellent results in terms of the use of health services. The integrated care model reduced the number of unplanned visits by $57 \%$ and the number of hospital admissions related to the main chronic disease of each patient by $50 \%$. Half of the published reviews on integrated care interventions between 2000 and 2015 reported significant reductions in hospital activity, ranging from $15 \%$ to $50 \%$ [23]. This places the reported results for the integrated care program within the top margin of positive results, and supports the notion of system-wide cross-organizational care pathways as a successful way to implement integrated care in contrast to smaller and narrow interventions [2]. Finally, regarding the economic impact, integrated care generated savings from US $\$ 584$ to $\$ 1434$ per patient and was cost-effective. This is in line with reviews stating the potential cost-effectiveness of integrated care for the management of chronic diseases [24]. Our results are also in line with savings found in other chronic diseases such as diabetes mellitus (from -1508 to +299 Euro; approximately US $\$-1809$ to +359 ) or schizophrenia (from -3860 to +614 Euro; approximately US $\$-4632$ to 737 ) [25].

\section{Implications for Research and Practice}

The need for people-centered integrated care, capable of providing an adequate response to the needs of growing populations of older people with chronic conditions while keeping costs sustainable, has been clearly stated by the World Health Organization [26]. In the frame of the CONNECARE project, an mHealth-enabled integrated care model was co-designed through an iterative process that involved all of the key stakeholders: patients, hospital and primary care medical and technical staff, social carers, managers, developers, and researchers. This coproduction multidisciplinary team had a clear focus on the patient and was ready to consider system-wide cross-organizational care pathways. The resulting mHealth-enabled integrated care model was thus perfectly aligned with the 2015 World Health Organization report on aging and health [1], which states that care providers should ensure that: (i) the assessment of individual impairments/declines in capacity is used to inform the development of a comprehensive care plan, and all domains are assessed together; (ii) interventions encouraging physical exercise are included in the care plans; and (iii) the presence of any impairment/decline in capacity triggers actions for the medical assessment of associated diseases. Moreover, we identified key features to be included in successful integrated care models for elder CCP: (i) the involvement of informal caregivers, being key in the adoption of mHealth tools such as self-management apps and sensors, and making the overall user experience very satisfactory [27]; (ii) the enablement of a common web-based platform for the coordination of care across settings and patient follow up; and (iii) the enhancement of communication channels for patients, which reduced the need of face-to-face appointments for quick consultations or questions. This latter aspect is especially relevant when patients are depending on others for travel to the general practitioners' offices or primary care centers.

\section{Conclusion}

The implementation of a patient-centered mHealth-enabled integrated care model empowering patients and connecting primary, hospital, and social care professionals reduced unplanned contacts with the health system and health costs, and was cost-effective. This supports the notion of system-wide cross-organizational care pathways using mHealth tools as a successful way to implement integrated care.

\section{Acknowledgments}

This work was supported by the European Union's Horizon 2020 Research and Innovation Program (under grant agreement GA-689802). JdB acknowledges receiving financial support from the Catalan Health Department (Pla Estratègic de Recerca i 
Innovació en Salut [PERIS] 2016: SLT002/16/00364) and Instituto de Salud Carlos III (ISCIII; Miguel Servet 2019: CP19/00108), cofunded by the European Social Fund (ESF), "Investing in your future." The funding organizations had no role in the design and conduct of the study; collection, management, analysis, and interpretation of the data; preparation, review, or approval of the manuscript; and decision to submit the manuscript for publication. The authors would like to express their sincerest gratitude to all of the participating patients and their carers, as well as all of the involved health and social care professionals, who were key in the co-design of the integrated care model and its implementation in the region of Lleida.

\section{Authors' Contributions}

$\mathrm{JdB}, \mathrm{EV}, \mathrm{NN}, \mathrm{FM}, \mathrm{FB}$, and GT participated in the conceptualization of project. MM, EV, AF, MB, and GT conducted data collection. MM, EV, and JdB participated in data curation. JdB conducted all statistical analyses. JdB wrote the original draft of the manuscript. All authors reviewed the final manuscript. JdB, EV, FM, FB, and GT secured funding for the project. The CONNECARE-Lleida group at Institut de Recerca Biomedica de Lleida, Lleida, Spain: Maria Aguilà Balastegui, Sandra Alexandre Loxano, Laila Al-Jouja Llorente, Tomás Alonso Sancho, Enrique Aparicio Bañeres, Ana Arce Vila, Jose Maria Baron Burriel, Ramon Bascompte Claret, Albert Bigorda Sague, Emilia Blanco Ponce, Maria Boldú Franque, Àngels Bosch Roig, Carmen Bravo Santiago, Alba Capdevila Sarramona, Aida Castelló Corretge, Jordi Colomina Morales, Montse Coma Gassó, Fina Cregenzan Ortiz, Dolors Del Pozo Garcia, Reis Drudis Morell, Mireia Falguera Vilamajó, Pere Farre Pagés, Yolanda Fauria Garcia, Anabel Fusalba Canales, Jara Gayan Ordas, Sergi Godia Lopez, Irene Gomez Companys, Jessica Gonzàlez Gutierrez, Anna Gort Oromí, Carme Jorge Tufet, Mercé Lavega Llorens, Laia Llort Samsó, Maria Rosa Lopez Cervelló, Belen Malla Clua, Josep Maria Marsol Mas, Teresita Martí Ribes, Diana Martin Capella, José Maria Martínez Barriuso, Esther Mateus Solé, Ramon Mazana Novellon, Petra Merino De los Santos, Miquel Mesas Julio, Sonia Minguet Vidal, Nuria Moles Porta, Luis Miguel Montaña Esteban, Dolors Morera Roset, Meritxell Moyà Oro, Irene Muñoz Del Campo, Francisco Nicolás Sánchez, Inés Ortiz Catalán, Mireia Ortiz Valls, Sonia Ortiz Congost, Jose Maria Palacin Peruga, Francesc Pallisó Folch, Eugeni Paredes Costa, Pablo Pastor Pueyo, Ana Pérez Sainz, Antonio Plana Blanco, Anna Planas Hiraldo, Pepita Pont Aldoma, Marife Quelle Alonso, Rebeca Ramirez Molinero, Maria Àngels Revés Juanbaro, Anna Ribé Miró, Eva Ribó Caubet, Rebeca Rodriguez Corbaton, Marina Rué Florensa, Oscar Sacristán García, Irene Sanmartí Forns, Maria Cruz Sanz Martinez, Neus Sendra Bordes, Montse Torra Riera, Maria Cruz Urgelés Castillón, Laia Utrillo Montagut, Montse Vidal Ballesté.

\section{Conflicts of Interest}

None declared.

\section{Multimedia Appendix 1}

Online supplement.

[DOCX File, 1567 KB-Multimedia Appendix 1]

\section{References}

1. World Report on Ageing and Health. World Health Organization. 2015. URL: https://www.who.int/ageing/events/ world-report-2015-launch/en/ [accessed 2020-12-09]

2. Harvey G, Dollard J, Marshall A, Mittinty MM. Achieving Integrated Care for Older People: Shuffling the Deckchairs or Making the System Watertight For the Future? Int J Health Policy Manag 2018 Apr 01;7(4):290-293 [FREE Full text] [doi: 10.15171/ijhpm.2017.144] [Medline: 29626395]

3. World Health Organization. Integrated care for older people: guidelines on community-level interventions to manage declines in intrinsic capacity. Geneva, Switzerland: World Health Organization (WHO); 2017.

4. Dates M, Lennox-chhugani N, Sant H, Pereira A, Tedeschi M. Health system performance assessment - Integrated Care Assessment (20157303 HSPA). Luxembourg: European Commission; 2018. URL: https://ec.europa.eu/health/sites/health/ files/systems performance assessment/docs/2018 integratedcareassessment en.pdf [accessed 2020-12-09]

5. Chouvarda IG, Goulis DG, Lambrinoudaki I, Maglaveras N. Connected health and integrated care: Toward new models for chronic disease management. Maturitas 2015 Sep;82(1):22-27. [doi: 10.1016/j.maturitas.2015.03.015] [Medline: 25891502]

6. The CONNECARE project. URL: http://www.connecare.eu/ [accessed 2020-03-19]

7. eCAP. URL: http://salutweb.gencat.cat/ca/ambits actuacio/linies dactuacio/tecnologies informacio i comunicacio/ecap/ [accessed 2020-03-19]

8. Reisberg B, Ferris S, de Leon MJ, Crook T. The Global Deterioration Scale for assessment of primary degenerative dementia. Am J Psychiatry 1982 Sep;139(9):1136-1139. [doi: 10.1176/ajp.139.9.1136] [Medline: 7114305]

9. van Walraven C, Dhalla IA, Bell C, Etchells E, Stiell IG, Zarnke K, et al. Derivation and validation of an index to predict early death or unplanned readmission after discharge from hospital to the community. CMAJ 2010 Apr 06;182(6):551-557 [FREE Full text] [doi: 10.1503/cmaj.091117] [Medline: 20194559]

10. Fitbit Flex 2 digital activity tracker. URL: http://www.fitbit.com/in/flex2 [accessed 2020-08-25] 
11. Withings. URL: http://www.withings.com/ [accessed 2020-08-25]

12. Charlson ME, Pompei P, Ales KL, MacKenzie C. A new method of classifying prognostic comorbidity in longitudinal studies: development and validation. J Chronic Dis 1987;40(5):373-383. [doi: 10.1016/0021-9681(87)90171-8] [Medline: 3558716]

13. Ware J, Kosinski M, Keller SD. A 12-Item Short-Form Health Survey: construction of scales and preliminary tests of reliability and validity. Med Care 1996 Mar;34(3):220-233. [doi: 10.1097/00005650-199603000-00003] [Medline: $\underline{8628042]}$

14. Collin C, Wade DT, Davies S, Horne V. The Barthel ADL Index: a reliability study. Int Disabil Stud 1988;10(2):61-63. [doi: 10.3109/09638288809164103] [Medline: $\underline{\text { 3403500] }}$

15. Zigmond AS, Snaith RP. The hospital anxiety and depression scale. Acta Psychiatr Scand 1983 Jun;67(6):361-370. [doi: 10.1111/j.1600-0447.1983.tb09716.x] [Medline: 6880820]

16. Pfeiffer E. A short portable mental status questionnaire for the assessment of organic brain deficit in elderly patients. $\mathrm{J}$ Am Geriatr Soc 1975 Oct;23(10):433-441. [doi: 10.1111/j.1532-5415.1975.tb00927.x] [Medline: 1159263]

17. CVE-DOGC-A-13051031-2013: Resolution SLT/353/2013, of February 13, on the review of public prices for the services provided by the Catalan Health Institute. URL: https://www.comb.cat/Upload/Documents/4635.pdf [accessed 2020-03-19]

18. Józsa T. The relevance of mobile applications helping in doctor-patient relationships. Br J Gen Pract 2020 Mar;70(692):109. [doi: 10.3399/bjgp20X708377] [Medline: $\underline{\text { 2107220] }}$

19. Aznar-Tortonda V, Palazón-Bru A, la Rosa DMF, Espínola-Morel V, Pérez-Pérez BF, León-Ruiz AB, et al. Detection of frailty in older patients using a mobile app: cross-sectional observational study in primary care. Br J Gen Pract 2020 Jan;70(690):e29-e35 [FREE Full text] [doi: 10.3399/bjgp19X706577] [Medline: 31685541]

20. Mitra S, Sambamoorthi U. Disability prevalence among adults: estimates for 54 countries and progress toward a global estimate. Disabil Rehabil 2014;36(11):940-947. [doi: 10.3109/09638288.2013.825333] [Medline: 23962193]

21. Borgermans L, Devroey D. A Policy Guide on Integrated Care (PGIC): Lessons Learned from EU Project INTEGRATE and Beyond. Int J Integr Care 2017 Sep 25;17(4):8 [FREE Full text] [doi: 10.5334/ijic.3295] [Medline: 29588631]

22. Flanagan S, Damery S, Combes G. The effectiveness of integrated care interventions in improving patient quality of life (QoL) for patients with chronic conditions. An overview of the systematic review evidence. Health Qual Life Outcomes 2017 Sep 29;15(1):188 [FREE Full text] [doi: 10.1186/s12955-017-0765-y] [Medline: 28962570]

23. Damery S, Flanagan S, Combes G. Does integrated care reduce hospital activity for patients with chronic diseases? An umbrella review of systematic reviews. BMJ Open 2016 Nov 21;6(11):e011952 [FREE Full text] [doi:

10.1136/bmjopen-2016-011952] [Medline: 27872113]

24. Cronin J, Murphy A, Savage E. Can chronic disease be managed through integrated care cost-effectively? Evidence from a systematic review. Ir J Med Sci 2017 Nov;186(4):827-834. [doi: 10.1007/s11845-017-1600-5] [Medline: 28477328]

25. Desmedt M, Vertriest S, Hellings J, Bergs J, Dessers E, Vankrunkelsven P, et al. Economic impact of integrated care models for patients with chronic diseases: a systematic review. Value Health 2016;19(6):892-902 [FREE Full text] [doi:

10.1016/j.jval.2016.05.001] [Medline: 27712719]

26. Global strategy on people-centred and integrated health services. World Health Organization. Geneva, Switzerland; 2015 Mar. URL: https://www.who.int/servicedeliverysafety/areas/people-centred-care/global-strategy/en/ [accessed 2020-12-09]

27. Vargiu E, Dorado A, Massip M, Gómez-Martínez M, Torres G, de Batlle J, et al. User Experience in CONNECARE: Results and Lessons Learnt in Lleida. XPA \& Health Com 2019;2 [FREE Full text]

\author{
Abbreviations \\ CCP: complex chronic patients \\ CONNECARE: Personalised Connected Care for Complex Chronic Patients \\ EMR: electronic medical records \\ ER: emergency room \\ ICER: incremental cost-effectiveness ratio \\ mHealth: mobile health \\ QoL: quality of life \\ SACM: Smart Adaptive Case Management \\ SF-12: 12-Item Short-Form Survey
}


Edited by G Eysenbach; submitted 04.07.20; peer-reviewed by I Cano, J Roca; comments to author 08.08.20; revised version received 31.08.20; accepted 29.10.20; published 14.01.21

Please cite as:

de Batlle J, Massip M, Vargiu E, Nadal N, Fuentes A, Ortega Bravo M, Miralles F, Barbé F, Torres G, CONNECARE-Lleida Group Implementing Mobile Health-Enabled Integrated Care for Complex Chronic Patients: Intervention Effectiveness and Cost-Effectiveness Study

JMIR Mhealth Uhealth 2021;9(1):e22135

URL: https://mhealth.jmir.org/2021/1/e22135

doi: $10.2196 / 22135$

PMID: 33443486

CJordi de Batlle, Mireia Massip, Eloisa Vargiu, Nuria Nadal, Araceli Fuentes, Marta Ortega Bravo, Felip Miralles, Ferran Barbé, Gerard Torres, CONNECARE-Lleida Group. Originally published in JMIR mHealth and uHealth (http://mhealth.jmir.org), 14.01.2021. This is an open-access article distributed under the terms of the Creative Commons Attribution License (https://creativecommons.org/licenses/by/4.0/), which permits unrestricted use, distribution, and reproduction in any medium, provided the original work, first published in JMIR mHealth and uHealth, is properly cited. The complete bibliographic information, a link to the original publication on http://mhealth.jmir.org/, as well as this copyright and license information must be included. 